\section{The effects of social media opinion leaders' recommendations on followers' intention to buy}

\author{
Renata Huhn Nunes \\ Jorge Brantes Ferreira \\ Pontificia Universidade Católica do Rio de Janeiro, \\ Department of Business Administration, Rio de Janeiro, Brazil
}

\begin{abstract}
Angilberto Sabino de Freitas
Unigranrio, Department of Business Administration, Rio de Janeiro, Brazil
\end{abstract}

\section{Fernanda Leão Ramos}

Pontifícia Universidade Católica do Rio de Janeiro,

Department of Business Administration, Rio de Janeiro, Brazil

\begin{abstract}
Purpose - The objective of this study is to investigate how consumers are influenced in their intention to buy after having access - within social media - to persuasive messages sent out by digital opinion leaders.

Design/methodology/approach - Data collection carried out via survey and data analysis carried out with the use of structural equation modeling.
\end{abstract}

Findings - Digital opinion leaders capable of generating persuasive messages can change the attitudes of followers and make them accept the information provided, influencing their intention to buy evaluated products.

Originality/value - The results show that it was possible to verify the direct and positive relationship between the persuasiveness of a message and the acceptance of the information contained in this message, while also indicating a significant relationship between the persuasiveness of the message and attitude change in relation to the purchase of goods evaluated by it. This highlights the relevance of these digital opinion leaders to the definition of marketing strategies by companies.

Keywords - Virtual social media; digital opinion leaders; information acceptance; attitude; intention to buy.
Received on

$01 / 16 / 2017$

Approved on

09/07/2017

Responsible editor:

Prof. Dr. Susana Costa e Silva

Evaluation process:

Double Blind Review 


\section{Introduction}

The rapid expansion of the internet's popularity has made this environment attractive to people and businesses. The network is intended not only to be a form of entertainment, but also a platform for consumers to exchange experiences and preferences referring to consumer brands (Araujo \& Neijens, 2012). Reviews by internet users are a type of electronic word-of-mouth, and are important sources of information in the decision-making process of other consumers (Wei \& Lu, 2013). This occurs because the psychological processes of individuals are subject to social influences (Deutsch \& Gerard, 1955).

Due to their limited capacity of mental processing, people need to find ways to simplify their decision-making (Merwe \& Heerden, 2009). Recommendations help consumers to reduce the amount of information to be processed and to filter the large amount of products/services available in virtual shopping environments, guiding them to a smaller set of alternatives that meet their specific needs (Kumar \& Benbasat, 2006). Thus, online consumers are people who are active in their quest for information, looking for texts referring to their interests, interpreting and making judgments about the messages received, in order to understand their content and adapt them to their own problems and situations (Rieh, 2002).

One of the main sources of electronic word-of-mouth are opinion leaders (Shi \& Wojnicki, 2014). Opinion leaders are individuals who can influence thoughts, attitudes or the behavior of other people, leading them to act in a certain way at a certain frequency (Rogers, 1983). Consumers routinely adopt strategies to reduce their decision-making risks (Leal, Hor-Meyll, \& Pessoa, 2014) and the opinion leaders act as agents for risk reduction, through experimentation and evaluation (Cho, Hwang, \& Lee, 2012).

In this context, this study is based on the relationship between online opinion leaders and their followers, who receive several evaluations and need to decide if they will accept or discard them in their decision-making processes. Thus, the main objective of this study is to propose a conceptual model to assess if persuasive messages can lead to acceptance by the consumers of information given by social media opinion leaders, and, also, to what extent the messages on products and services affect consumer behavior regarding the consumption of the recommended products or services and their intention to buy them.

The acceptance of information is a topic widely studied and discussed in academia (Cheung, Lee, \& Rabjohn, 2008; Cheung, Luo, Sia, \& Chen, 2009; Cheung \& Thadani, 2012; Sussman \& Siegal, 2003; Teng, Khong, Goh, \& Chong, 2014a). However, there are few studies referring to the determinants and potential of the messages on consumption on online social networks (Teng et al., 2014a). This paper, therefore, seeks to contribute to the literature expanding the studies on the impact of word-ofmouth messages on the acceptance of information (Teng et al., 2014a) to specifically assess opinion leadership in online social media. Moreover, this study extends the research on the influence of the attributes of information on the adoption of information for consumption purposes, by adding their impact to the purchase intention of social media users who read this information and to the attitude of potential consumers.

\section{Literature review}

\section{I Opinion leadership, behavior and social media}

The concept of opinion leadership refers to an individual's ability to influence in a social network. Opinion leaders are the most influential group in social systems (Rogers, 1983). When potential consumers are not yet familiar with a product/service, they associate a high degree of uncertainty and risk to its purchase. Therefore, the adoption of this product/service depends on an individual's predisposition to test new features 
and form his or her own perception on the product (Ortega, 2011). Compared with people who seek information, the opinion leaders generally have more experience and more information on the product/service category, have greater involvement with it, and display a more exploratory and innovative behavior (Lyons \& Henderson, 2005). Thus, we can see the importance of opinion leaders, whose main features are innovative behavior, the knowledge of a given category of products/services, and their power to influence others (Eck, Jager \& Leeflang, 2011).

In the digital era, in which one can use the internet as a source of consultation for both news and reviews, the discussion on the influence of certain groups in the dissemination of information should be expanded to the online environment (Merwe \& Heerden, 2009). Digital opinion leaders are those who use online spaces, such as blogs, forums, social networks and other forms of online social media actively and in a collaborative manner (San Jose-Cabezudo, Camarero-Izquierdo \& Rodriguez-Pinto, 2012). They can influence people in three main ways: serving as a model to be copied, through word-of-mouth advertising, or by giving advice on purchase and use (Merwe \& Heerden, 2009). Digital opinion leaders attract a lot of attention from internet users and play a key role in word-of-mouth advertising, generating messages and content of use to other people (Meng, Wei \& Zhu, 2011), influencing people's attitudes.

An attitude is an assessment, through a continuum, with positive and negative characteristics acting as anchors, that an individual makes through an association of knowledge, meanings and beliefs (Peter \& Olson, 2009). This assessment allows for the examination of the personal relevance of a certain concept and whether one has a favorable or unfavorable position towards it (Cheung \& Thadani, 2012). For example, a consumer's attitude concerning whether he/she has gathered enough information varies from strongly positive to strongly negative (Nolder \& Kadous, 2017). So, attitudes may differ in direction (positive vs. negative) and/or strength (strong vs. weak). The power of such attitude determines the extent to which it influences the behavior (Petty, Haugtved, \& Smith, 1995). Thus, attitudes are a precursor of judgments and decisions (Petty et al., 1995).

This can be followed by an action by the individual, or not (Ajzen \& Fishbein, 1977). Attitudes already formed by individuals may, however, act as mediators of behavior, influencing their purchase intention (Cheung \& Thadani, 2012; Rocha, Ferreira, \& Silva, 2013). Attitudes are always referring to a specific concept, whether physical or social objects, policies or other people (Ajzen \& Fishbein, 1977) and are not necessarily intense or extreme, and may be negative, neutral or positive.

The emergence of online social media encompasses texts, images, videos and social networks (Berthon, Pitt, Plangger, \& Shapiro, 2012) and has amplified the ability to share and spread the content generated by users. By exchanging messages, digital social media users can interact and exchange information through various channels such as blogs, social networks, forums, virtual communities, sharing platforms and virtual worlds, among many others (Teng et al., 2014a).

Within this scenario, Instagram is one of the digital social media platforms that is being most used by opinion leaders to express their opinions on products and services. Instagram was created so that users could share photos, and presently also allows for short videos (Silva, Melo, Almeida, Salles, \& Loureiro, 2013). Users interact through comments on published photos or through "likes."

\subsection{Acceptance of information theory}

The theory of limited rationality indicates that when a person is making a choice, that person does not have access to all the information available on that subject and, even if they did, they would not have the ability to process and evaluate it all (Merwe \& Heerden, 2009). A way to facilitate their decision-making is through 
recommendations from other users that give useful information on the products (Kumar \& Benbasat, 2006).

Deutsch and Gerard (1955) proposed the Dual-Process Theory (DPT) model to evaluate social influences on individuals' judgments. According to this model, two types of influence can affect a person's decisions: normative and informational influences. Normative influences are those that seek to make an individual act in accordance with the expectations of others. Informational influences, in their turn, are those referring to the acceptance of information passed on by others as evidence of reality. DPT suggests that the first motivator of attitudinal changes and, consequently, behavior, is external information (Bhattacherjee \& Sanford, 2006). New information introduces other possibilities, causing one to think about different alternatives and possibly change the attitude towards a certain subject.

Another recognized model on the adoption of information is the Elaboration Likelihood Model (ELM), proposed by Petty and Cacioppo (1984). According to the ELM, the informational influence can occur in any part of the user's decision-making process (Cacioppo, Petty, Kao \& Rodriguez, 1986; Sussman \& Siegal, 2003). For Petty and Cacioppo (1984), an individual is never totally profound or totally careless in his or her assessment of messages. Depending on the situations presented, each person will show different levels of depth in processing incoming messages. These different levels are presented in a continuous space, which goes from a central route to the peripheral route.

By following the central route, an individual interprets and assesses the arguments contained in an informational message and uses cognitive elaborations to assume a rational positioning on their validity (Wu \& Shaffer, 1987). If arguments are considered to be of quality, people tend to consider the information useful (Bhattacherjee $\&$ Sanford, 2006). A user may often use his/ her perceptions on the source of information (heuristic evaluation) to assist in the assessment and judgment of the quality of the arguments (systematic evaluation) (Chaiken \& Maheswaran, 1994). If there is a predominance of heuristic evaluations, it is said that the peripheral route was followed, that is, the merits of the position held were rated based on tips or inferences on the source of information. The type of assessment that will be more influential to the consumer (which route they will follow) depends on the activity that is being searched (Rieh, 2002). In a situation of high relevance (high motivation or a strong capacity to judge the information), a person tends to follow the central route. However, in situations of low relevance (less motivation or capacity to judge), they tend to take the peripheral route (Petty \& Cacioppo, 1984). Studies have shown that the assessment of information by means of the central and peripheral routes was not directly referring to the use of the information (Sussman $\&$ Siegal, 2003). The assessment of users leads to the acceptance or rejection of the message as a useful source of information.

\subsection{Persuasive messages and purchase intention}

Using the basis of the acceptance of information theories, Figure 1 shows the proposed conceptual model. The constructs and hypotheses discussed below were used to formulate the study of both the direct effects of persuasive messages on the acceptance of information and attitude, as well as their indirect effects on purchase intention. 


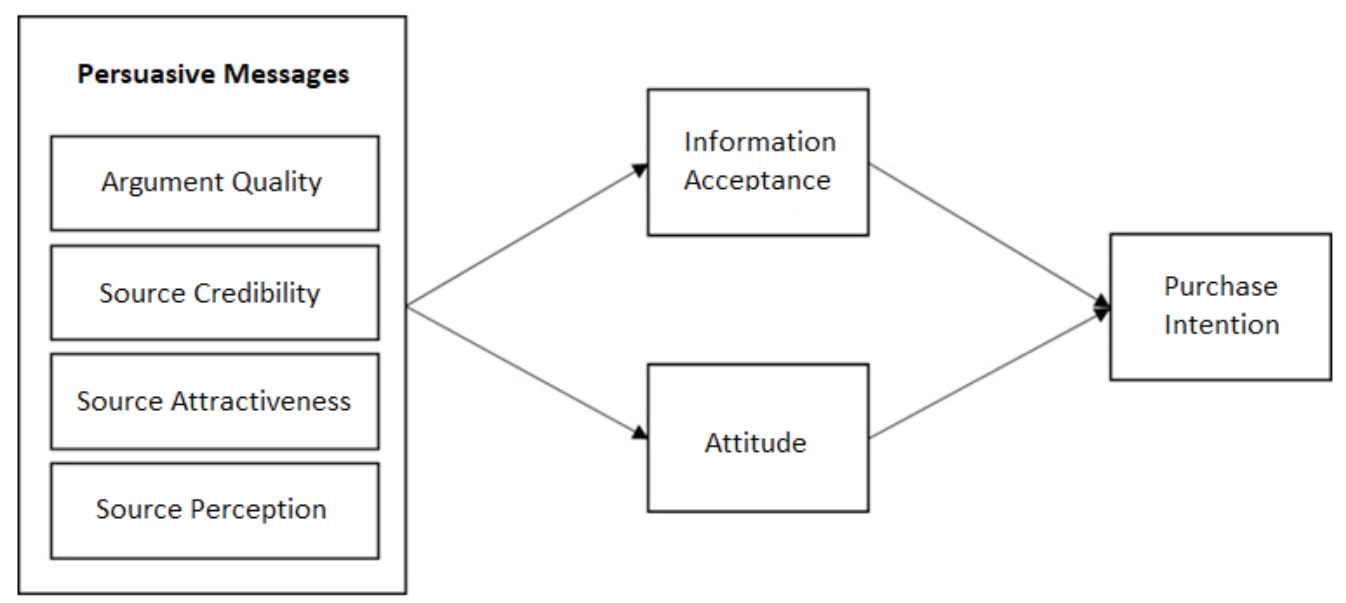

Figure 1. Proposed conceptual model

\subsection{Persuasive messages}

As mentioned above, the ELM is recognized as a model of two-way information processing. The central route involves a more careful evaluation of persuasive messages, while the peripheral route leads to a reduced process of assessment of the messages by the recipients. The model is considered suitable to explain persuasive messages in social media, because it explains the dual process and the various effects on cognitive information processing (Teng, Khong, \& Goh, 2014b). Tang, Jang and Morrison (2012) studied information processing by dual routes in the context of travel sites and confirmed that people are more likely to consider persuasive messages through the central route when they're relatively involved. For example, users are more likely to carefully evaluate information on the web if the content is more detailed and has more reviews by other users (Tam \& Ho, 2005). However, people are more likely to go through the peripheral route if they can exert less cognitive effort by following heuristics rules (Tang et al., 2012). Thus, Teng et al. (2014a) argue that, for a message to be persuasive and follow the central route, it must possess four characteristics: argument quality, source credibility, source attractiveness, and source perception. Therefore, according to Teng et al. (2014b), the persuasiveness of a message is the ability of an online message to be perceived as a reliable source of information by those receiving it, and capable of influencing the attitude of that individual.

The quality of an argument is referring to how information is perceived and evaluated. It should be assessed according to the consumers' point of view, after all they are the ones who will judge whether the argument is suitable for use (Wang \& Strong, 1996). For this work, it will be validated in terms of completeness (breadth and depth), accuracy, timeliness, relevance, and strength of argument (Wixom \& Todd, 2005; Cheung et al., 2008; Cheung et al., 2009; Teng et al., 2014a).

Those who receive the information do not consider only the features of the message. If the message follows the peripheral route, the individual will assess the message without analyzing its arguments (Sussman \& Siegal, 2003; Bahttacherjee \& Sanford, 2006). One of the ways to assess the message through tips concerning its merits is to consider aspects referring to the credibility of the source (Cheung et al., 2008). The credibility of the source is the measure of to what extent a source of information is perceived as being competent and reliable (Sussman $\&$ Siegal, 2003; Bahttacherjee \& Sanford, 2006). In this work, the credibility of the source is assessed based on knowledge (expertise on the product), 
trust and prior experience of the transmitter with the evaluated product (Wu \& Shaffer, 1987; Wu \& Wang, 2011; Teng et al., 2014a). People tend to believe messages transmitted by sources that are considered highly credible and to accept information transmitted through them more easily (Cheung et al., 2009).

Another possible assessment made by the users of the information is the attractiveness of the source. The attractiveness of the source means how pleasant the recipients of information consider the source, and involves concepts such as the similarity of opinions, familiarity and sympathy between transmitter and receiver (Teng et al., 2014a). Another factor that can influence the credibility of information is the perception on the source, which can be examined according to the utility and serviceability (how the message is capable of assisting in obtaining knowledge) of the information and research (Rogers, 1983; Hsu, Lin, \& Chiang 2013; Teng et al., 2014a). Moreover, individuals tend to associate with people who have common interests (Teng et al., 2014a).

\subsection{Acceptance of information and attitude}

Unlike messages' persuasiveness, which concerns the aspects associated with the message that may influence or not an individual's behavior, the acceptance of information is a process in which people intentionally engage in the use of information, i.e. it is an aspect intrinsic to the individual during a process in which the individual purposefully judges if the information received is reliable and can be used in their consumption decision making (Cheung et al., 2008; Cheung et al., 2009; Cheung \& Thadani, 2012). Also, according to the ELM, the central route involves careful examination of messages before shaping an attitude, while the peripheral route relies on environmental cues in the message to decide whether to accept it or not. In this integrative structure, the persuasiveness of a message refers to the force or plausibility of a message's persuasive argument (Eagly \& Chaiken,
1993). So, if a person perceives the message as credible information, they tend to accept that type of information (Zhang \& Watts, 2008; Teng et al., 2014a). Consequently, hypothesis 1 is thus proposed:

H1: The persuasiveness of the message has a direct and positive effect on the acceptance of the information by the consumer.

ELM explains how the characteristics of individuals and their respective settings interact to affect the cognitive processing of individuals' decision-making (Petty \& Cacioppo, 1986). Thus, according to the ELM, individuals, when exposed to arguments, may experience changes in their attitudes by the central or peripheral route, depending on their involvement with the product or service under assessment (Petty \& Cacioppo, 1984; Cacioppo et al., 1986). Therefore, it can be assumed that exposure to persuasive messages is a fact that is capable of changing the attitude of those who receive such messages, influencing that user's predisposition to buy the recommended products or services (Hsu et al., 2013). Therefore:

\section{H2: The persuasiveness of the message has a direct and positive effect on the attitude of individuals regarding the purchase of the products/services recommended by opinion leaders.}

\subsection{Purchase intention}

Purchase intention is understood as the desire to purchase a product in the future (Cheung \& Thadani, 2012). The relationship between purchase intention and actual buying behavior is based on the fact that individuals make decisions based on the information available. Thus, a person's intention to take action is the immediate determinant of their actual behavior (Ajzen \& Fishbein, 1980) The relationship between attitude and purchase intention is well established and validated in the literature of online consumer behavior. For example, Chang, Cheung, and Lai 
(2005) found that the attitude consistently has a significant impact on online purchase intention. This is also corroborated by Hsu et al. (2013), who revealed how a positive attitude can influence individuals' purchase intention in online shopping environments.

Moreover, in studies on online word-ofmouth communication, online recommendations are also a kind of social influence, especially when given by opinion leaders (Cheung \& Thadani, 2012). Therefore, it is expected that the adoption of information has a direct effect on consumers' purchase intention. So the following hypotheses are proposed:

H3: The acceptance of information has a direct and positive effect on the intention to buy the evaluated products/services.

H4: The attitude of individuals regarding the purchase of the products/services recommended by online opinion leaders has a direct and positive effect on the purchase intention of the evaluated products/services.

\section{Methodology}

A survey with a non-probabilistic sample of the population of interest was carried out to test the hypotheses formulated for the study. There already is a reasonable number of scholarly articles referring to the proposed research problem, including studies that define models that employ some of the variables in question here (Cheung et al., 2008; Cheung et al., 2009; Cheung \& Thadani, 2012; Hsu et al., 2013; Teng et al., 2014a).

Data was collected through online surveys. The surveys were sent through a link posted on the main page of the Instagram account "Comprei e Aprovei" ("I Bought and Approved"). Surveys were submitted online, because the research problem deals with the recommendations by online social media opinion leaders. Thus, the respondents, by definition, should make use of these online networks. Therefore, the sample is composed solely of people who have access to the internet and access online social media, particularly the Instagram account "Comprei e Aprovei" (Calder, Malthouse, \& Schaedel 2009). By submitting the survey through the internet, the respondents are captured within the same environment (the internet) in which the object of study is accessed (online social media - the "Comprei e Aprovei" Instagram account), decreasing the possibility of bias and guaranteeing that respondents have homogeneous knowledge of the opinion leader in question (Carneiro \& Dib, 2011).

\section{I Operationalizing the variables}

This study uses scales already developed and tested in literature for the measurement of all the constructs involved in the structure of the proposed model. Therefore, scales from previous studies were used to measure the dimensions' argument quality, credibility, attractiveness and perception of the source, and the constructs acceptance of information, attitude, and purchase intention (Dodds Monroe \& Grewal, 1991; Wu \& Wang, 2011; Hsu et al., 2013; Teng et al., 2014a), with modifications to suit the context of social media opinion leaders.

- Quality of argument: scale by Teng et al. (2014a), composed of 14 items.

- Source credibility: scale by Teng et al. (2014a), composed of 4 items.

- Source attractiveness: scale by Teng et al. (2014a), composed of 3 items.

- Source perception: scale by Teng et al. (2014a), composed of 3 items.

- Acceptance of information: scale by Teng et al. (2014a), composed of 2 items.

- Attitude: original scale by Fishbein \& Ajzen (1975), adapted by Hsu et al. (2013), composed of 3 items.

- Purchase intention: original scale by Dodds et al. (1991) adapted by Wu \& Wang (2011), composed of 4 items.

The items included in the survey instrument were translated into Portuguese by professional translators, using translation and 
back-translation steps to ensure that the scales in Portuguese were as close as possible to the original.

We conducted a pretest of the survey with a small group of people with a profile similar to that of the population under study, to assess the understanding of the respondents on this first version of the questionnaire. The results obtained with this initial pretest served to refine the questionnaire and to prepare a new version. This second version was also submitted to a second pretest. At this opportunity the participants were also instructed to provide their assessment of the questionnaire, while we checked if any additional adjustments were required to the translation and the presentation of the survey. With the results of the second pretest, the final survey instrument was prepared, with a total of 33 items measured through the use of five-point Likert scales, in addition to eight items relating to demographic variables.

\subsection{Sample and data collection procedures}

The study's population was composed of Brazilian users of social media sites who use these networks to follow and monitor accounts of online opinion leaders. The sample selection was carried out by choosing the account of an opinion leader that had many followers and whose posts fit the objective of this study: to assess the effects of the messages of a given opinion leader on consumer purchase intention. Among the several accounts of Brazilian opinion leaders in social networks that were considered, the selected account was "Comprei e Aprovei," which had about 140,000 of followers on Instagram and is dedicated solely to the evaluation of products and services; in it, the account administrator often publishes pictures and text with reviews on products and services that she purchased. The availability of the account administrator, Raquel, to help the researchers by applying the questionnaires directly to her followers was another reason for selecting this Instagram account in particular, among several other opinion leaders with the wanted profile that were initially considered. After establishing contact with Raquel, we made a partnership with her to perform the survey with her own network of followers. She agreed to publish the link to the survey on her feed, inviting her followers to answer the questionnaire. However, because the page has a mostly female audience, just the answers from females were considered in the research.

The decision to choose only one opinion leader (Raquel) and place the questionnaire in a specific type of online social media (Instagram) was made with the purpose of uniformity of the conditions of the respondents. By limiting the application of the questionnaire to a specific account, we sought to ensure that respondents were assessing the same messages and that the focus of their assessment would be the same content, message type, person of influence, and social networking site. This approach aimed to avoid the interference of external effects to the study on the responses to the questionnaire.

A total of 228 responses were obtained, and 24 questionnaires were eliminated because their respondents were under 15 and over 50 years old (11 people) or male (13 people). Thus, the final sample was composed of 204 valid respondents. Of these, most of the participants were young, with the largest number of respondents between the ages of 20 and 24 (34\%) and between 25 and 29 (23\%). Mean age was 25.1 years old. Of the total, $80.9 \%$ of respondents have high school or undergraduate education, with the latter having the highest number of responses $(46.6 \%)$. Note that there is a prevalence of answers that indicate experience in the use of online social media, as $92.6 \%$ claim to have more than three years of access to online social media, and 83.3\% reported accessing these networks more than ten times per week. Regarding the interaction with the "Comprei e Aprovei" account, 78 people (38.2\%) claimed to often read the page's posts, 52 (25.5\%) reported always reading them, and $44(21.6 \%)$ stated reading the posts almost always. Most of the respondents $(95.1 \%)$ stated having wanted to buy a product or service that they saw being evaluated in "Comprei e Aprovei;" a smaller number (47.1\%) actually bought a product evaluated by her. 


\section{Results}

\section{I Measurement model}

A confirmatory factor analysis (CFA) was performed to test the validity, unidimensionality and reliability of the scales used in the measurement. Several indexes (incremental and absolute) were used to evaluate the adjustment of the proposed measurement model. After several iterations refining the model, the final measurement model, with 27 indicators, presented good adjustment rates $(\mathrm{RMSEA}=0.069$ with C.I. of 0.061 to 0.077 ; CFI $=0.938$; IFI $=0.940$; TLI $=0.920$; $\chi 2 /$ d.f. $=1.976, \mathrm{p}<0,001)$.

The face validity for all scales used was guaranteed during the development of the survey instrument (choice of scales already used in literature, careful translation and pretests). The correlation matrix between constructs was examined to verify nomological validity: all the correlations were significant and in the expected direction. Regarding the convergent validity, the average variance extracted (AVE) was calculated for each construct. All the calculated AVE values were between 0.51 and 0.71 , indicating the convergent validity of the scales used. With respect to internal consistency and reliability of the scales, all the employed scales met the minimum reliability levels considered adequate by the literature (Fornell \& Larcker, 1981), showing values between 0.72 and 0.88 for the alpha coefficient, and between 0.73 and 0.94 for composed reliability. Finally, all the shared variances were below the variance extracted through the items that measure each of the constructs, indicating appropriate discriminant validity.

\subsection{Structural model}

Structural Equation Modeling (SEM) was used to test the proposed model and the hypotheses of the research. All the fit indices showed a good adjustment of the model to the data. The reason $\chi 2 /$ d.f. was 2.76 , below the 3.0 value suggested by Byrne (2010). Moreover, the incremental adjustment indices were above 0.90 , with a CFI of 0.907, a TLI of 0.901, and an IFI of 0.909. The absolute adjustment indices, in their turn, were under the 0.08 limit established by literature $(\mathrm{Hu}$ \& Bentler, 1999; Hair, Black, Babin, Anderson, \& Tatham, 2009; Byrne, 2010), also indicating a good adjustment of the model. The RMSEA was 0.073 (C.I of 0.066 to 0.079 ) and the SRMR was 0.075 . Given these rates, the conclusion is that the adjustment of the proposed model is satisfactory.

After verifying the adjustment of the proposed structural and measurement models, the coefficients estimated for the casual relationships between the constructs were examined (Table 1 and Figure 2). Verification of each of the research hypotheses was performed by analyzing the magnitude, direction, and significance of the standardized coefficients, estimated by means of the structural model, with all hypotheses being verified.

Table 1

\section{Estimated standardized coefficients, hypotheses, and significance}

\begin{tabular}{lccc}
\hline Proposed relationship & $\begin{array}{c}\text { Standardized } \\
\text { coefficient }\end{array}$ & $\begin{array}{c}\text { p-value } \\
\text { hypothesis }\end{array}$ & $\begin{array}{c}\text { Verified } \\
\text { hy }\end{array}$ \\
\hline $\mathrm{H}_{1}:$ Persuasive messages $\rightarrow$ Acceptance of information & 0.61 & $<0.001$ & yes \\
$\mathrm{H}_{2}:$ Persuasive messages $\rightarrow$ Attitude & 0.86 & $<0.001$ yes & $<0.011$ yes \\
$\mathrm{H}_{3}:$ Acceptance of Information $\rightarrow$ Purchase intention & 0.20 & 0.73 & $<0.001$ yes \\
$\mathrm{H}_{4}:$ Attitude $\rightarrow$ Purchase intention & & &
\end{tabular}




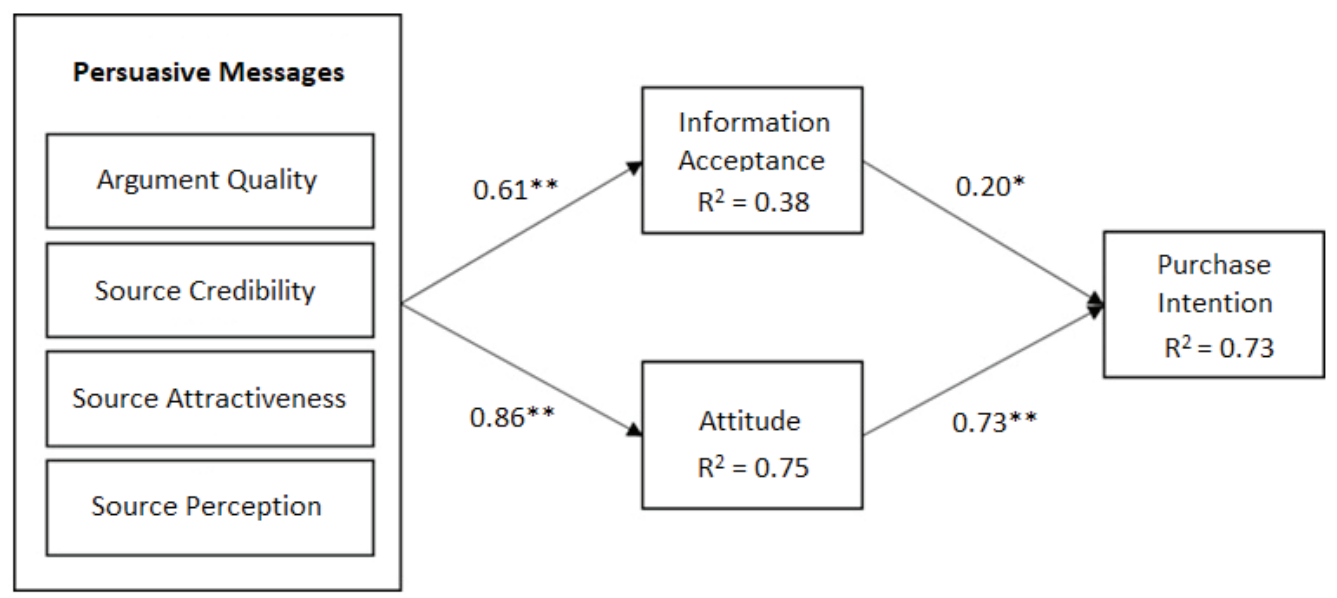

Figure 2. Estimated standardized coefficients for the proposed model (* indicates p-value $<0.05,{ }^{* *}$ indicates p-value $\left.<0.001\right)$

The extent to which the variability of each dependent variable was explained by the independent variables was also assessed. As described in Figure 2, attitude and purchase intention had good portion of their variances explained (75\% and $73 \%$, respectively), while the acceptance of information had $38 \%$ of its variance explained. Although these results suggest a model with high explanatory power, they indicate that there might be other constructs and relationships capable of explaining other parts of the variance present in the constructs in question, which were not considered in this model.

\section{Discussion}

The focus of this study were messages about consumption transmitted by online opinion leaders in digital social media. The results show that consumers, after receiving a message and considering it persuasive, tend to accept this information as a reliable and useful source for purchase decisions. As mentioned earlier in this work, the persuasiveness of a message is subjectively assessed by those that receive it through dimensions such as quality of the argument, source credibility, attractiveness of the source, and perception on the source.

The authors believe that the determinant attributes of persuasive messages (quality of the argument, credibility, attractiveness and perception of the source) play significant roles in the success of creating persuasive messages in social media. In other words, persuasive messages can be more successful in generating changes in attitudes of social media users, influencing purchase intention.

In the proposed model, the change in attitude and behavioral intentions have been integrated with the processing routes described in the ELM model to explain how individuals process information, with the intent of predicting and understanding the influences of persuasive messages on consumer behavior. It was found that the opinion leader, through electronic word-ofmouth, may use the ELM structure to identify and measure the impacts of influential messages, based on the attributes that make them more persuasive.

The results show that the persuasiveness of a message presented direct, significant and positive effects on the acceptance of information (magnitude of 0.61) and attitude towards purchase (0.86). These findings indicate that once the receiver of the information assesses it as persuasive, they see it not only as a compelling message, but also as a reliable evaluation that can be used in their consumer decision process. More than believing in the transmitted information, the potential consumer judges the message as being 
a useful source of knowledge that can be used in future purchasing decisions.

The strongest observed effect referred to attitudinal change. The message perceived as more persuasive can cause the individual who receives it to create a favorable attitude referring to the consumption of the products recommended by online opinion leaders. Given that the transmitted information was previously considered as being of quality and that the source of information was conceived as credible and attractive (persuasive message), it is understood that this can lead to a more favorable assessment in relation to the purchase of the products indicated by that online opinion leader. As proposed by the DPT model, the first motivator of attitudinal change is external information (Bhattacherjee \& Sanford, 2006), which is in line with the encountered results and with what had been stated in the research hypothesis.

However, the model only explained 38\% of the variability of the acceptance of information construct. This indicates that there may be other constructs capable of explaining the acceptance of information and that have not been considered in this study. There may be other factors that lead a message to be considered persuasive and that were not included in the model, reducing its effect on the acceptance of the persuasive message. Teng et al. (2014a) propose that the persuasiveness of a message can also be referring to the style of that message. According to the authors, visual information such as images, videos and prints, as well as aspects such as the number of "likes" (the button that indicates that the followers of the online opinion leader saw and approved the post), comments in the message, and the degree of interaction between the digital opinion leader and their followers have significant impact on the acceptance of information by consumers. Another proposition is that consumers tend to believe less in recommendations of digital opinion leaders when they realize that the message is an advertisement and not a spontaneous review (Shi \& Wojnicki, 2014). Similarly, there may be external factors, in addition to the persuasiveness of the message, which lead to a greater acceptance of information by the person who receives it. Cheung \& Thadani (2012) indicate that contextual factors also interfere in the acceptance of information, such as the platform on which the evaluation is made, which may affect the perception of the reliability of the information.

In the case of the "Comprei e Aprovei" account and the online opinion leader Raquel, these results indicate that a follower of this account sees a post on a product or service and tends to believe that the reviews made by Raquel are trustworthy and, therefore, are influenced by them. By believing that the messages from "Comprei e Aprovei" are compelling, its followers also have a more favorable position regarding the purchase of the products that are indicated by Raquel.

Studies propose that positive attitudes regarding the purchase lead to an increase in the intent to purchase that product or service (Chang et al., 2005; Cheung \& Thadani, 2012). This relationship was verified in this research, with a magnitude of 0.73 This indicates that the people who adopt a positive attitude as to the purchase of products recommended by digital opinion leaders tend to develop the intent to purchase that product. A favorable attitude is not necessarily followed by a behavior favorable to the object (Ajzen \& Fishbein, 1977), but in the model presented it was found that changes in attitude caused by persuasive messages can lead to an increase in the desire to purchase the product reviewed by an opinion leader. This result shows that, within online shopping environments, a relevant way to influence consumers' buying behavior is to try to shape a positive attitude referring to those products and services. Persuasive messages can play an important role in this sense, seeking to establish parameters for stimulating the emergence of a positive attitude through the attributes of the message, such as quality of the argument, credibility, attractiveness and perception of the source. 
Cheung \& Thadani (2012) suggested that the acceptance of word-of-mouth messages would lead to an intention to buy the products evaluated in the message. This study encountered such connection (magnitude of 0.20). Despite the low magnitude of the standardized coefficient of this relationship, the direct and positive relationship was significant, as expected. This indicates that when a potential consumer accepts a message as a useful and reliable source of information, they are inclined to want to buy the product evaluated in the message. Thus, one can see the importance of an opinion leader's message. The information they transmit, in addition to being considered useful by the consumer, can be a source of information that directs the consumer to want to purchase the evaluated product.

Specifically, in the case of the "Comprei e Aprovei" account, the followers who accept the information and have a favorable attitude toward buying the products or services indicated by Raquel tend to have the intention to purchase what is being recommended. This shows that a post on of the "Comprei e Aprovei" account has the potential to make its followers desire and consider purchasing the reviewed products or services. Finally, social networks create a continuous flow of communication in which the information, reviews, and recommendations on products and services can converge interactively and in a timely manner with consumers, influencing the attitude of individuals throughout these interactions.

\section{Conclusions}

This study set out to investigate the ability of persuasive messages to influence the purchase intention of consumers, seeking to examine if messages from an online opinion leader can influence the acceptance of the information by the individual and result in an attitudinal change towards the consumption of the goods reviewed by that leader. Based on the ELM, in which there are two distinct routes to process information, according to the inherent characteristics of the message, the claim is that the persuasiveness of the messages can affect the attitude and purchase intention of consumers, resulting in theoretical and managerial implications.

There are four contributions to the theory. First, the proposed model verified the direct and positive relation between the persuasiveness of a message and the acceptance of the information contained in that message. It also verified the relationship between the persuasive message and the attitudinal change referring to the purchase of the goods assessed by the individual. Moreover, it intended to investigate how the acceptance of information transmitted by opinion leaders and the attitude of consumers in relation to the consumption of products recommended by them influences the purchase intention of consumers seeking information on online social media. The study showed that both constructs (acceptance of information and attitude) have significant effects on the purchase intention, suggesting that consumers exposed to a persuasive message would be more likely to want to buy the product or service being described in the message.

The second contribution was to align two research lines that were being treated separately: the theories of external information as modifiers of attitude and theories on the persuasiveness of messages referring to the acceptance of information. To do so, a parsimonious model was proposed to assess the effects of the power of persuasion of messages provided by online opinion leaders on consumers' attitude and acceptance of information, which, in turn, affect the individuals' purchase intention.

Third, the model proposed in this research advances the understanding of the topic by including the construct attitude in the model proposed by Teng et al. (2014a). Based on the arguments of Cheung and Thadani (2012), the importance of the relationship between attitude and purchase intention is clear. Thus, the model present in this study includes this relationship in the list of proposed hypotheses, increasing the understanding of the studied phenomena.

Finally, the fourth contribution was to focus the discussion on a specific type of word- 
of-mouth communication: the one carried out by online opinion leaders, in particular those who are active in online social media. The study suggests the power that these opinion-makers have when they share their opinions on products and services on social networks, creating messages that can persuade consumers to form positive or negative attitudes referring to their purchase intentions.

Regarding managerial contributions, three points are worthy of highlight. First, according to the results presented herein, marketing professionals must realize that social medial is playing a key role in reaching clients and building relationships. In this sense, these social media networks may influence consumers' behavior regarding their attitudes towards products and services. Thus, online persuasive messages must be carefully stimulated and managed by marketers with the purpose of influencing the consumers' purchase intention. Alliances between companies and online opinion leaders can be strategic to increase awareness on the product or brand, as well as actual sales. The study suggests that companies should partner up with opinion leaders to have their products reviewed and recommended to the leader's followers. The recommendation is for marketers to involve their client-base directly through social media platforms in association with opinion leaders to leverage greater positive attitude from the members of online communities.

Secondly, instead of investing so much money in traditional marketing, companies must recognize the importance of word-of-mouth communication and integrate it into their overall marketing strategy. By understanding the impact and effectiveness of persuasive messages in the electronic word-of-mouth, marketers will be able to design more effective marketing campaigns. In other words, marketing managers can use the results of this study as guidelines to obtain competitive advantage in the ever-changing business scenario, seeking ways to use the power of opinion leaders and their persuasive messages to form a positive attitude towards their products and services. Thus, marketing strategies need to consider the role of the opinion leader and their influence on the target audience. This works shows to the companies the importance of the influence of online opinion leaders on a consumer's intention to purchase a product reviewed by such leaders. Managers must be aware of the increasing power that these digital leaders have over the brands and should be aware that online word-of-mouth marketing can be a strong ally, as consumers have more trust in what their peers are talking about on social media than in traditional advertisements.

Thirdly, online opinion leaders can also check how relevant their messages are to their followers, as what they say can influence the buying behavior of those who follow their posts on social media. As the study showed, there are some characteristics that lead consumers to consider a message as more persuasive: the quality of the message transmitted (the wealth of details, reliability, relevance, timeliness, comprehensibility) and aspects of the communicator themselves (their competence and reliability, knowledge, previous experiences, pleasantness, empathy, and similarity of tastes with the reader of the messages). By understanding these aspects, the opinion leaders can work their messages to make them even more persuasive to the consumer.

The limitations of the study are due to the fact that all questionnaire responses came solely from the followers of a single opinion leader (Raquel, owner of the "Comprei e Aprovei" account) inside a single social media network (Instagram). Although this was a conscious and justified decision to ensure homogeneity and consistency of responses, the model tested only the vision of the people who follow this account. Thus, the relationships verified in the research cannot be generalized to all and any type of opinion leader or social media network.

Regarding future research, we recommend conducting studies that extend the application of the proposed model to different profiles of online opinion leaders on different online social media networks, expanding the scope of the results 
obtained by this research. Future research may also explore other scales for the constructs used in the model proposed in this study; for example, they may add other dimensions to explain the construct "persuasive messages," or seek more information on the "acceptance of the information" construct. Another option would be a smaller number of scales to assess the persuasiveness of a message, which would simplify the model, making it easier to be applied.

\section{References}

Ajzen, I., \& Fishbein, M. (1977). Attitudebehavior relations: A theoretical analysis and review of empirical research. Psychological Bulletin, 84(5), 888-918.

Ajzen, I., \& Fishbein, M. (1980). Understanding attitudes and predicting social behavior. Englewood Cliffs, NJ: Prentice-Hall.

Araujo, T., \& Neijens, P. (2012). Friend me: Witch factors influence top global brands participation in social network sites. Internet Research, 22(5), 626-640.

Berthon, P., Pitt, L., Plangger, K., \& Shapiro, D. (2012). Marketing meets web 2.0, social media, and creative consumers: Implications for international marketing strategy. Business Horizons, 55, 261-271.

Bhattacherjee, A., \& Sanford, C. (2006). Influence processes for information technology acceptance: An elaboration likelihood model. MIS Quarterly, 30(4), 805-825.

Byrne, B. (2010). Structural equation modeling with AMOS: Basic concepts, applications and programming (2nd ed.). New York: Routledge.

Cacioppo, J., Petty, R., Kao, C., \& Rodriguez, R. (1986). Central and peripheral routes to persuasion: An individual difference perspective. Journal of Personality and Social Psychology, 51(5), 1032-1043.
Calder, B., Malthouse, E., \& Schaedel, U. (2009). An experimental study of the relationship between online engagement and advertising effectiveness. Journal of Interactive Marketing, 23(4), 321-331.

Carneiro, J., \& Dib, L. (2011). O uso da internet em surveys: Oportunidades e desafios. Administração: Ensino e Pesquisa, 12(4), 641-670.

Chaiken, S., \& Maheswaran, D. (1994). Heuristic processing can bias systematic processing: Effects of source credibility, argument ambiguity, and task importance on attitude judgment. Journal of Personality and Social Psychology, 66(3), 460-473.

Chang, M., Cheung, W., \& Lai, V. (2005). Literature derived reference models for the adoption of online shopping. Information Management 42(4), 543-559.

Cheung, C., Lee, M., \& Rabjohn, N. (2008). The impact of electronic word-of-mouth: The adoption of online opinions in online customer communities. Internet Research, 18(3), 229-247.

Cheung, M., Luo, C., Sia, C., \& Chen, H. (2009). Credibility of electronic word-of-mouth: Informational and normative determinants of online consumer recommendations. International Journal of Electronic Commerce, 13(4), 9-38.

Cheung, C., \& Thadani, D. (2012). The impact of electronic word-of-mouth communication: A literature analysis and integrative model. Decision Support Systems, 54(1), 461-470.

Cho, Y., Hwang, J., \& Lee, D. (2012). Identification of effective opinion leaders in the diffusion of technological innovation: A social network approach. Technological Forecasting \& Social Change, 79(1), 97-106.

Deutsch, M., \& Gerard, H. (1955). A study of normative and informational social influences upon individual judgment. Journal of Abnormal and Social Psychology, 51(3), 629-636. 
Dodds, W., Monroe, K., \& Grewal, D. (1991). Effect of price, brand, and store information on buyers' product evaluation. Journal of Marketing Research, 28(3), 307-319.

Eagly, A., \& Chaiken, A. (1993). The Psychology of Attitudes. Fort Worth, TX: Harcourt, Brace, Jovanovich.

Eck, P., Jager, W., \& Leeflang, P. (2011). Opinion leaders' role in innovation diffusion: A simulation study. Product Innovation Management, 28(2), 187-203.

Fishbein, M., \& Ajzen, I. (1975). Belief, Attitude, Intention and Behavior: An Introduction to Theory and Research. Reading, MA: Addison-Wesley Publishing.

Fornell, C., \& Larcker, D. (1981). Evaluating structural equation models with unobservable variables and measurement error. Journal of Marketing Research, 18(1), 39-50.

Hair, J., Black, B., Babin, B., Anderson, R., \& Tatham, R. (2009). Análise Multivariada de Dados (6a ed.). Porto Alegre: Bookman.

Hsu, C., Lin, J., \& Chiang, H. (2013). The effects of blogger recommendations on customers' online shopping intentions. Internet Research, 23(1), 69-88.

Hu, L., \& Bentler, P. (1999). Cutoff criteria for fit indexes in covariance structure analysis: Conventional criteria versus new alternatives. Structural Equation Modeling, 6(1), 1-55.

Kumar, N., \& Benbasat, I. (2006). Research note: the influence of recommendations and consumer reviews on evaluations of websites. Information Systems Research, 17(4), 425-349.

Leal, G., Hor-Meyll, L., \& Pessoa, L. (2014). Influence of virtual communities in purchasing decisions: The participants' perspective. Journal of Business Research, 67(5), 882-890.
Lyons, B., \& Henderson, K. (2005). Opinion leadership in a computer-mediated environment. Journal of Consumer Behavior, 4(5), 319-329.

Meng, F., Wei, J., \& Zhu, Q. (2011). Study on the impacts of opinion leader in online consuming decision. Proceedings of the international Joint Conference on Service Sciences, 140-144.

Merwe, R., \& Heerden, G. (2009). Finding and utilizing opinion leaders: Social networks and the power of relationships. South African Journal of Business Management, 40(3), 65-76.

Nolder, C. J., \& Kadous, K. (2017). Grounding professional skepticism in mindset and attitude theory: A way forward. [Working paper] Suffolk University and Emory University. Recuperado de SSRN: http://dx.doi.org/10.2139/ssrn.2524573

Ortega, B. (2011). The role of post-use trust in the acceptance of a technology: Drivers and consequences. Technovation, 31(10-11), 523-538.

Peter, J., \& Olson, J. (2009). Comportamento do consumidor e estratégia de marketing (8a ed.). São Paulo: McGraw-Hill.

Petty, R., \& Cacioppo, J. (1984). Source factors and the elaboration likelihood model of persuasion. Advances in Consumer Research, 11, 668-672.

Petty, R., Haugtvedt, C., \& Smith, S. (1995). Elaboration as a determinant of attitude strength: Creating attitudes that are persistent, resistant, and predictive of behavior. In R. E. Petty, \& J. A. Krosnick (Eds.), Attitude strength: Antecedents and consequences (pp. 93-130). New York, NY: Psychology Press.

Rieh, S. (2002). Judgement of information quality and cognitive authority in the web. Journal of American Society for Information Science and Technology, 53(2), 145-161.

Rocha, A., Ferreira, J. B., \& Silva, J. F. (2013). Administração de Marketing: Conceitos, Estratégias e Aplicaçóes. (1 ${ }^{\mathrm{a}}$ Ed.). Rio de Janeiro: Atlas. 
Rogers, E. (1983). Diffusion of Innovations (3rd ed.). New York: Free Press.

San Jose-Cabezudo, R., Camarero-Izquierdo, C., \& Rodriguez-Pinto, J. (2012). En busca de los evangelizadores digitales: Por qué las empresas deben identificar y cuidar a los usuários más activos de los espacios de opiniones online. Universia Business Review, 35, 14-31.

Shi, M., \& Wojnicki, A. (2014). Money talks... to online opinion leaders: What motivates opinion leaders to make social-network referrals? Journal of Advertising Research, 54(1), 81-91.

Silva, T., Melo, P., Almeida, J., Salles, J., \& Loureiro, A. (2013). A picture of Instagram is worth more than a thousand words: workload characterization and application. Proceedings of the International Conference on Distributed Computing in Sensor Systems, 123-132.

Sussman, S., \& Siegal, W. (2003). Informational influence in organizations: An integrated approach to knowledge adoption. Information Systems Research, 14(1), 47-65.

Tam, K., \& Ho, S. (2005). Web personalization as a persuasion strategy: An elaboration likelihood model perspective. Information Systems Research, 16(3), 271-291.

Tang, L., Jang, S., \& Morrison, A. (2012). DualRoute communication of destination websites. Tourism Management, 33(1), 38-49.

Teng, S., Khong, K., Goh, W., \& Chong, A. (2014a). Examining the antecedents of persuasive eWOM messages in social media. Online Information Review, 38(6), 746-768.
Teng, S., Khong, K., \& Goh, W. (2014b). Conceptualizing Persuasive Messages Using ELM in Social Media, Journal of Internet Commerce, 13(1), 65-87.

Wang, R., \& Strong, D. (1996). Beyond accuracy: What data quality means to data consumers. Journal of Management Information Systems, 12(4), 5-33.

Wei, P., \& Lu, H. (2013). An examination of the celebrity endorsements and online customer reviews influence female consumers' shopping behavior. Computers in Human Behavior, 29(1), 193-201.

Wixom, B., \& Todd, P. (2005). A theoretical integration of user satisfaction and technology acceptance. Information Systems Research, 16(1), 85-102.

Wu, C., \& Shaffer, D. (1987). Susceptibility to persuasive appeals as a function of source credibility and prior experience with the attitude object. Journal of Personality and Social Psychology, 52(4), 677-688.

Wu, P., \& Wang, Y. (2011). The influences of electronic word-of-mouth message appeal and message source credibility on brand attitude. Asia Pacific Journal of Marketing and Logistics, 23(4), 448-472.

Zhang, W., \& Watts, S. (2008). Capitalizing on content: Information adoption in two online communities. Journal of the Association for Information Systems 9(2), 73-94. 


\section{Supporting agencies:}

FAPERJ

\section{Authors:}

1. Renata Huhn Nunes, Master in Business Administration, Pontifícia Universidade Católica do Rio de Janeiro, Brazil. E-mail: renatahn@gmail.com

ORCID

(iD) 0000-0002-0135-7963

2. Jorge Brantes Ferreira, Doctor in Business Administration, Universidade Federal do Rio de Janeiro, Brazil.E-mail: jorge.brantes@gmail.com

\section{ORCID}

(D) 0000-0002-9579-4477

3. Angilberto Sabino de Freitas, Doctor in Business Administration, Pontifícia Universidade Católica do Rio de Janeiro, Brazil. E-mail: angilberto.freitas@gmail.com

\section{ORCID}

(i) 0000-0002-9329-1745

4. Fernanda Leáo Ramos, Master in Business Administration, Pontifícia Universidade Católica do Rio de Janeiro, Brazil. E-mail: leaoramos@gmail.com

ORCID

(D) 0000-0001-6352-8812

\section{Contribution of each author:}

\begin{tabular}{|c|c|c|c|c|}
\hline Contribution & $\begin{array}{l}\text { Renata Huhn } \\
\text { Nunes }\end{array}$ & $\begin{array}{l}\text { Jorge Brantes } \\
\text { Ferreira }\end{array}$ & $\begin{array}{c}\text { Angilberto Sabino } \\
\text { de Freitas }\end{array}$ & $\begin{array}{c}\text { Fernanda Leão } \\
\text { Ramos }\end{array}$ \\
\hline 1. Definition of research problem & $\sqrt{ }$ & $\sqrt{ }$ & & \\
\hline $\begin{array}{l}\text { 2. Development of hypotheses or research questions } \\
\text { (empirical studies) }\end{array}$ & $\sqrt{ }$ & $\sqrt{ }$ & & \\
\hline $\begin{array}{l}\text { 3. Development of theoretical propositions } \\
\text { (theoretical work) }\end{array}$ & - & - & - & - \\
\hline 4. Theoretical foundation/Literature review & $\sqrt{ }$ & & $\sqrt{ }$ & $\sqrt{ }$ \\
\hline 5. Definition of methodological procedures & & & $\sqrt{ }$ & \\
\hline 6. Data collection & $\sqrt{ }$ & & & \\
\hline 7. Statistical analysis & & $\sqrt{ }$ & & \\
\hline 8. Analysis and interpretation of data & $\sqrt{ }$ & $\sqrt{ }$ & $\sqrt{ }$ & $\sqrt{ }$ \\
\hline 9. Critical revision of the manuscript & & & & $\sqrt{ }$ \\
\hline 10. Manuscript writing & $\sqrt{ }$ & $\sqrt{ }$ & $\sqrt{ }$ & $\sqrt{ }$ \\
\hline
\end{tabular}

